\title{
Acute Stent Thrombosis Following Concomitant Balloon Aortic Valvuloplasty and Percutaneous Coronary Intervention
}

\author{
Puneeth Shridhar1, Triston Smith ${ }^{2}$, Ramzi Khalil3, Gustav Eles ${ }^{3}$, David Lasorda ${ }^{3}$, Young Jae Chun ${ }^{1,4,5}$ \\ ${ }^{1}$ Department of Bioengineering, University of Pittsburgh, Pittsburgh, USA \\ ${ }^{2}$ Department of Cardiology, Wheeling Hospital, Wheeling, USA \\ ${ }^{3}$ Department of Cardiology, Allegheny General Hospital, Pittsburgh, USA \\ ${ }^{4}$ Department of Industrial Engineering, University of Pittsburgh, Pittsburgh, USA \\ ${ }^{5} \mathrm{McG}$ owan Institute for Regenerative Medicine, Pittsburgh, USA \\ Email: pus8@pitt.edu, yjchun@pitt.edu,rkhalil@wpahs.org, dlasorda@wpahs.org
}

How to cite this paper: Shridhar, P., Smith, T., Khalil, R., Eles, G., Lasorda, D. and Chun, Y.J. (2016) Acute Stent Thrombosis Following Concomitant Balloon Aortic Valvuloplasty and Percutaneous Coronary Intervention. World Journal of Cardiovascular Diseases, 6, 333-337.

http://dx.doi.org/10.4236/wjcd.2016.610038

Received: August 6, 2016

Accepted: October 7, 2016

Published: October 10, 2016

Copyright $\odot 2016$ by authors and

Scientific Research Publishing Inc.

This work is licensed under the Creative

Commons Attribution International

License (CC BY 4.0).

http://creativecommons.org/licenses/by/4.0/

\begin{abstract}
Balloon aortic valvuloplasty is often used as a palliative measure or as a bridge to transcatheter aortic valve replacement in the management of aortic stenosis in high risk or inoperable patients. Severe aortic stenosis coexisting with coronary artery disease is not uncommon. In these circumstances, adjuvant percutaneous coronary intervention may be warranted. The safety and efficacy of combined valve and coronary intervention strategies has been recently studied. An increased incidence of complications when both procedures are performed in the same setting may throw new challenges. We report a case of fatal acute stent thrombosis following balloon aortic valvuloplasty and percutaneous coronary intervention.
\end{abstract}

\section{Keywords}

Stent Thrombosis, Aortic Valvuloplasty, Percutaneous Coronary Intervention

\section{Introduction}

Coronary occlusion is a relatively rare complication of balloon aortic valvuloplasty (BAV) with an occurrence rate of 0.66 percent [1]. The presence of significant coronary artery disease in patients with aortic stenosis has brought about a necessity for combined BAV and percutaneous coronary intervention (PCI) techniques in nonsurgical patients. Herein, we describe the first case of acute stent thrombosis due to the combined coronary and valve intervention (CVI). 


\section{Case Report}

A 80-year-old woman presented to the hospital with progressive angina and dyspnea on exertion. Her relevant past history included known severe aortic stenosis, diabetes mellitus, dyslipidemia chronic kidney disease and paroxysmal atrial fibrillation. An echocardiogram revealed severe aortic stenosis with peak to mean gradient of $74 / 41$ $\mathrm{mm} \mathrm{Hg}$, left ventricular ejection fraction of $60 \%$. Diagnostic cardiac catheterization showed severe $90 \%$ stenosis of mid segment of the left anterior descending artery (LAD) followed by $70 \%$ diffuse stenosis (Figure 1). The rest of the coronaries has no significant obstructive disease.

The patient was evaluated by the cardio-thoracic surgical team and deemed unsuitable for surgical valve replacement because of multiple comorbidities and high surgical risk. She was brought to the cardiac catheterization lab. A signed informed consent was obtained from the patient's family.9F arterial access and 7F venous access was obtained via the right femoral artery and vein respectively. Decision was made to perform PCI to the LAD followed by BAV. The patient was already on Aspirin, did not receive any pre procedural Clopidogrel. She was given $0.75 \mathrm{mg} / \mathrm{kg}$ Bivalirudin bolus followed by 1.75 $\mathrm{mg} / \mathrm{kg} / \mathrm{hr}$ infusion. A $6 \mathrm{~F}$ guiding catheter (XB3, Cordis, NJ) was used for the percutaneous intervention. The lesion was pre-dilated with $2.5 \times 12 \mathrm{~mm}$ balloon (Voyager, Abbott Vascular, CA) at a pressure of 12 atms. Then, the residual lesion was covered with three bare metal stents in an overlapped fashion. Stents (Vision, Abbott Vascular, $\mathrm{CA}$ ) measuring $3.0 \times 15 \mathrm{~mm}, 3.0 \times 15 \mathrm{~mm}$ and $2.75 \times 23 \mathrm{~mm}$ were deployed, proximal to distal, at high pressures of 16 atms. Repeat angiography revealed no residual stenosis in the stented segment (Figure 2). Following that, balloon valvuloplasty on the aortic valve using $18 \times 40 \mathrm{~mm}$ balloon (Atlas, Bard peripheral vascular, AZ) was performed using the power injector and ultra dilute dye described previously by our group [2].

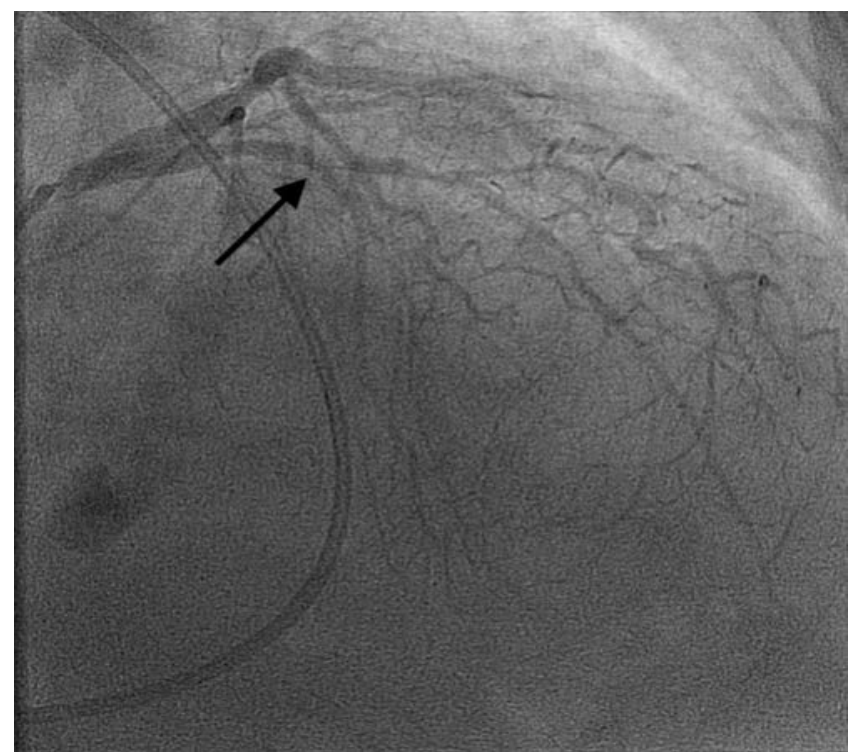

Figure 1. Coronary angiography showing severe $90 \%$ stenosis of mid segment of the left anterior descending artery (arrow) followed by $70 \%$ diffuse stenosis. 


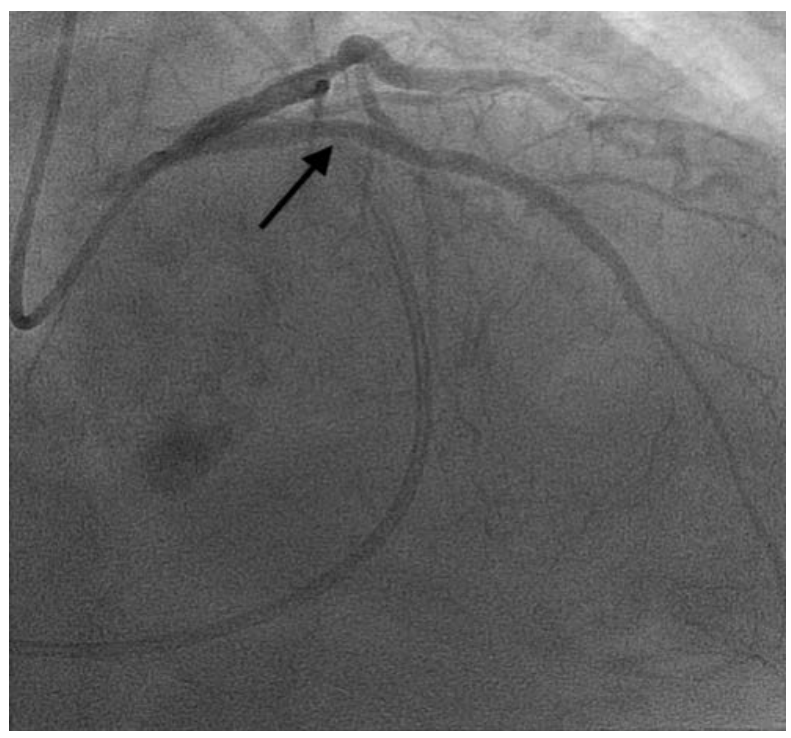

Figure 2. Coronary angiography showing no residual stenosis in the stented segment (arrow).

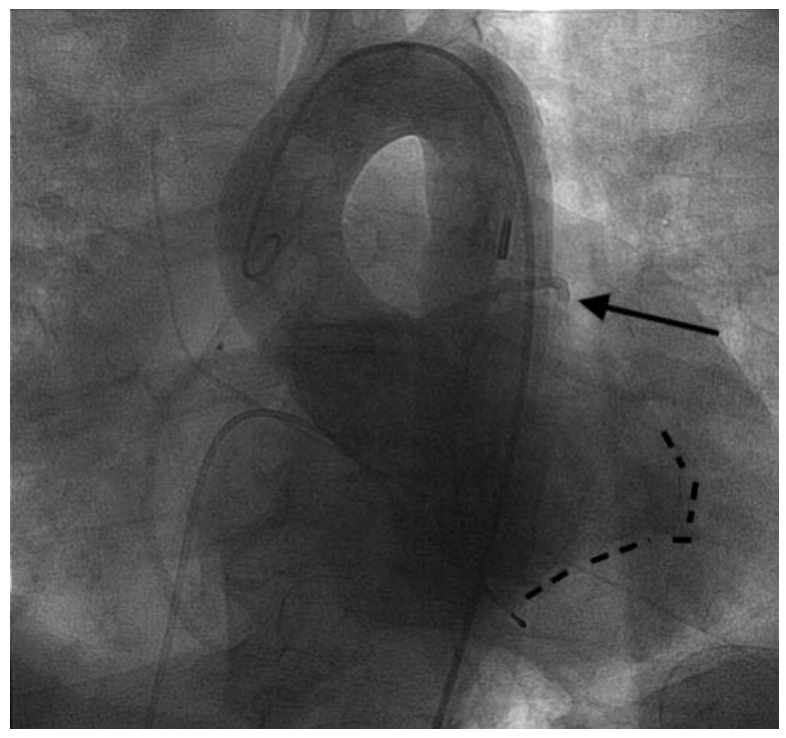

Figure 3. Aortography showing 4+ aortic regurgitation, anterolateral severe hypokinesis (dotted line) and acute stent thrombosis of the mid anterior descending artery (arrow).

Immediately, the patient experienced hypotension and sudden onset of chest pain. ST segment elevation (STEMI) was noted on the monitor. An IABP was rapidly inserted via the left common femoral arterial approach. Aortography revealed 4+ aortic regurgitation, anterolateral severe hypokinesis and acute stent thrombosis of the mild left anterior descending artery (Figure 3). Counterpulsation was discontinued. The patient was intubated and cardio pulmonary resuscitation was initiated. While doing $\mathrm{CPR}$, angioplasty and thrombectomy was performed on the LAD. Despite re-institution of TIMI 2 - 3 flow in the LAD, the patient was in cardiac standstill. The team leader at the point decided to stop further resuscitation efforts since the patient was not a candidate for surgical aortic valve replacement. 


\section{Discussion}

Coexisting coronary artery disease and aortic stenosis have been recently managed with concomitant PCI and BAV. Ben-Dor I. and his colleagues recently studied the feasibility of this strategy in 80 patients and found out it was safe and efficacious [3]. However, effect of PCI in the same setting on BAV outcomes is unknown.

Coronary occlusion is a known fatal complication of BAV. It can present as either late or acute myocardial infarction. Poor anticoagulation and calcium embolization from the aortic valve have been implicated as a possible mechanism. An additional mechanism could be transient left ventricular occlusion during valvuloplasty resulting in brief coronary vasoconstriction due to acute spikes in vasopressin [4]. We report the first case of acute stent thrombosis following combined BAV and PCI. In our case, the most likely reason of acute stent thrombosis is acute aortic regurgitation leading to hypotension and elevated left ventricular end diastolic pressure compromising coronary perfusion. This is in combination with lack of Clopidogrel preloading in the setting of Bivalirudin.

The advantage of adjunct PCI before BAV is theoretical as performing PCI will help to alleviate ischemia prior to rapid ventricular pacing and BAV. In our particular case, there was a fatal outcome since it contributed to the acute aortic regurgitation thus compromising hemodynamics, resulting in acute stent thrombosis. Our experience has influenced us to stage BAV and PCI unless there is a compelling reason to perform them in combination.

\section{Conclusion}

This case has altered our approach to intervention with concomitant coronary artery disease and severe aortic stenosis. We believe staging intervention may improve outcomes. Further investigations may be warranted.

\section{References}

[1] Ben-Dor, I., Pichard, A.D., Satler, L.F., Goldstein, S.A., Syed, A.I., Gaglia, M.A., et al. (2010) Complications and Outcome of Balloon Aortic Valvuloplasty in High-Risk or Inoperable Patients. JACC: Cardiovascular Interventions, 3, 1150-1156. http://dx.doi.org/10.1016/j.jcin.2010.08.014

[2] Eles, G.R., Fisher, D.L., Khalil, R., Dajani, Z., Spotti, J.P. and Lasorda, D. (2011) Balloon Aortic Valvuloplasty for Aortic Stenosis Using a Novel Percutaneous Dilation Catheter and Power Injector. Journal of Interventional Cardiology, 24, 92-98. http://dx.doi.org/10.1111/j.1540-8183.2010.00594.x

[3] Ben-Dor, I., Maluenda, G., Looser, P.M., Okubagzi, P., Torguson, R., Xue, Z., et al. (2013) Outcomes of Concomitant Percutaneous Coronary Intervention and Balloon Aortic Valvuloplasty. Catheterization and Cardiovascular Interventions, 82, 835-841. http://dx.doi.org/10.1002/ccd.23193

[4] de Lezo, J., Montilla, P., Pan, M., Romero, M., Sancho, M., de Castroviejo, J.R., et al. (1989) Abrupt Homeostatic Responses to Transient Intracardiac Occlusion during Balloon Valvuloplasty. American Journal of Cardiology, 64, 491-497. http://dx.doi.org/10.1016/0002-9149(89)90427-X 


\section{Abbreviations}

$\mathrm{BAV}=$ Balloon Aortic Valvuloplasty,

$\mathrm{PCI}=$ Percutaneous Coronary Intervention,

$\mathrm{CVI}=$ Coronary and Valve Intervention,

LAD = Left Anterior Descending,

STEMI = ST Elevation Myocardial Infarction,

IABP = Intra Aortic Balloon Pump,

$\mathrm{CPR}=$ Cardio Pulmonary Resuscitation.

Submit or recommend next manuscript to SCIRP and we will provide best service for you:

Accepting pre-submission inquiries through Email, Facebook, LinkedIn, Twitter, etc.

A wide selection of journals (inclusive of 9 subjects, more than 200 journals)

Providing 24-hour high-quality service

User-friendly online submission system

Fair and swift peer-review system

Efficient typesetting and proofreading procedure

Display of the result of downloads and visits, as well as the number of cited articles

Maximum dissemination of your research work

Submit your manuscript at: http://papersubmission.scirp.org/

Or contactwjcd@scirp.org 